\title{
ST-segment Elevation Following Cardioversion of Atrial Fibrillation in the Emergency Department: Unmasked Myocardial Infarction due to Left Main Coronary Artery Plaque Rupture or Unspecific Finding?
}

\author{
Dirk Prochnau, MD*; Ralf Surber, MD*; Matthias Hoyme, MD*; Sylvia Otto, MD*; Anna Selle, MD*; \\ Tudor C. Poerner, MD*
}

\section{ABSTRACT}

Atrial fibrillation (AF) is a frequent reason for emergency department visits. According to current guidelines either rate- or rhythm-control are acceptable therapeutic options in such situations. In this report, we present the complicated clinical course of a patient with $\mathrm{AF}$ and a rapid ventricular response. Because of paroxysmal $\mathrm{AF}$, the patient was on chronic oral anticoagulation therapy with warfarin. Pharmacological treatment was ineffective to control ventricular rate, and immediate synchronized electrical cardioversion was performed. One hour later, the patient complained of chest pain in combination with marked ST-segment elevation in the anterior leads. Cardiac catheterization with optical coherence tomography disclosed plaque rupture in the left main coronary artery without other significant stenosis. Stent implantation was performed successfully. During the course of the hospital stay, the patient remained asymptomatic and the ST-segment elevations resolved. However, despite treatment with amiodarone it was not possible to keep the patient permanently in sinus rhythm. Therefore, a biventricular pacemaker was implanted and AV node ablation performed.

\section{RÉSUMÉ}

La fibrillation auriculaire (FA) est un motif fréquent de consultation au service des urgences. Selon les lignes de conduite actuelles, le rétablissement ou de la fréquence cardiaque ou du rythme cardiaque sont des formes acceptables de traitement dans le contexte. Il sera question, dans le présent exposé, de l'évolution clinique, avec complications, d'un cas de FA accompagnée d'une réponse ventriculaire rapide. Comme le patient souffrait déjà de FA paroxystique, il était soumis à un traitement anticoagulant oral prolongé par la warfarine. Le traitement pharmacologique n'ayant pas permis de rétablir la fréquence ventriculaire, une cardioversion électrique synchronisée a été effectuée sans délai. Une heure plus tard, le patient a commencé à se plaindre de douleurs thoraciques, et une forte élévation du segment ST a été observée à l'électrocardiogramme, dans les dérivations antérieures. Les médecins ont alors procédé à un cathétérisme cardiaque avec tomographie par cohérence optique, qui a révélé la rupture d'une plaque dans le tronc coronaire gauche, sans autre signe important de sténose; l'examen a été suivi de la pose réussie d'une endoprothèse. Durant son séjour à l'hôpital, le patient est resté asymptomatique, et l'élévation du segment ST est disparue. Toutefois, malgré le traitement par l'amiodarone, le cœur ne s'est jamais maintenu en rythme sinusal d'une façon durable. Aussi l'arythmie a-t-elle justifié la pose d'un stimulateur cardiaque biventriculaire et l'ablation du nœud auriculo-ventriculaire.

Keywords: STEMI, immediate cardioversion, atrial fibrillation, plaque rupture, left main artery, emergency department

\section{INTRODUCTION}

Atrial fibrillation (AF) is associated with an increased risk of stroke, congestive heart failure, and all-cause

From the *Department of Internal Medicine, Jena University Hospital, Jena, Germany.

Correspondence to: Dirk Prochnau, Jena University Hospital, Erlanger Allee 101, Jena 07740, Germany; E-mail: dirk.prochnau@med.uni-jena.de 
mortality. ${ }^{1}$ It is a frequent reason for presenting to the emergency department (ED). In the United States, it accounts for approximately $1 \%$ of all ED visits. ${ }^{2}$ The management of this common arrhythmia is challenging. However, before starting a specific treatment it is important to consider why the patient is symptomatic and whether the $\mathrm{AF}$ is responsible for the symptoms. Instability might be due to other causes of acute illness like sepsis or gastrointestinal bleeding, and therefore, $\mathrm{AF}$ with a high heart rate may be only an epiphenomenon associated with these conditions.

Two competing strategies can be used for the management of recent-onset AF: rate-control or rhythmcontrol. Both approaches are acceptable according to current guidelines. ${ }^{3}$ Case series have confirmed the efficacy and safety of the rhythm-control strategy. ${ }^{4}$

Nevertheless, a conservative approach of observation may be considered, as up to $60 \%$ of patients with recent-onset $\mathrm{AF}$ will spontaneously convert to sinus rhythm in the first 24 hours after presentation, making pharmacologic or electrical cardioversion unnecessary. ${ }^{5}$ If performed in the ED, cardioversion should be used with caution in higher-risk patients. To mitigate the risk of stroke from embolization of left atrial appendage thrombus, acute cardioversion should only be considered in patients with symptoms of less than 48-hours duration or only after more than three weeks of therapeutic anticoagulation. ${ }^{3}$

\section{CASE REPORT}

An 83-year-old man was admitted to the ED because of increasing shortness of breath and palpitations during the previous weeks. The otherwise hemodynamically stable patient (blood pressure 155/112 mm Hg, heart rate $147 \mathrm{bpm}$ ) denied chest pain. Because of paroxysmal $\mathrm{AF}$, the patient was on chronic oral anticoagulation (OAC) therapy with warfarin (international normalized ratio (INR) at admission was 4.1). The use of intravenous beta-blocker ( $5 \mathrm{mg}$ of metoprolol) was ineffective in reducing his heart rate. Therefore, immediate cardioversion was performed successfully $(200 \mathrm{~J})$ and without complications (Figure 1A and 1B). Because of recurrent atrial runs, the patient subsequently received intravenous amiodarone $(300 \mathrm{mg})$. One hour later, the patient reported chest pain. The electrocardiogram (ECG) showed marked ST-segment elevation in the anterior leads (Figure 1C). Urgent cardiac catheterization via right radial artery disclosed an eccentric plaque in the left main coronary artery (LMCA) with TIMI 3 flow (Figure 2A). Quantitative coronary angiography (QCA) revealed stenosis severity of $30 \%$. There were no other significant stenosis in the left or right coronary arteries. Based on the vessels morphology and spontaneous restoration of flow in LMCA, an optical coherence tomography (OCT) was performed. OCT demonstrated an intimal disruption in the LMCA (Figure 2C). Therefore, a Xience V stent $(4.0 \times 8 \mathrm{~mm})$ was deployed (Figure 2B). After stent deployment, intracoronary OCT was repeated to evaluate stent placement and expansion. OCT revealed incomplete expansion (Figure 2D) and a second dilatation with a non-compliant balloon was necessary. The final OCT control demonstrated a good result with adequate stent expansion (Figure 2E). The ECG two hours after stenting of the LMCA showed poor R-wave progression but no ST-segment elevation (Figure 1D). High-sensitive cardiac troponin I level (Abbott ARCHITECT STAT high sensitive troponin I immunoassay, Wiesbaden, Germany) peaked at $168 \mathrm{pg} / \mathrm{mL}$ (normal, <34.2 pg/mL). Echocardiography revealed a dilated left ventricle $(61 \mathrm{~mm})$ with moderate reduced LV function (45\%) due to global hypokinesis. Five days after cardioversion, there was a recurrence of $\mathrm{AF}$ that was refractory to antiarrhythmic treatment with amiodarone (patient received $1,000 \mathrm{mg}$ oral amiodarone per day in divided doses until a total of $8 \mathrm{~g}$; then $200 \mathrm{mg}$ per day); as per standard guidelines ${ }^{6}$. Four weeks later, a biventricular pacemaker was implanted in preparation for the AV node ablation that was successfully performed at four weeks post pacemaker implantation. At this time point, a second attempt for cardioversion was not possible, because transesophageal echocardiography revealed thrombi in the left atrial appendage. Since restoration and maintenance of sinus rhythm was no longer the treatment goal, amiodarone was stopped.

\section{DISCUSSION}

This case may have educational value in two ways. First, it demonstrated that immediate cardioversion in a patient with unknown duration of $\mathrm{AF}$ should be done cautiously, especially if the patient is in a stable condition. In such cases, immediate cardioversion could be either ineffective in conversion to sinus rhythm or only effective for a short-term period like was the case for our patient. Furthermore, cardioversion may carry the 
A

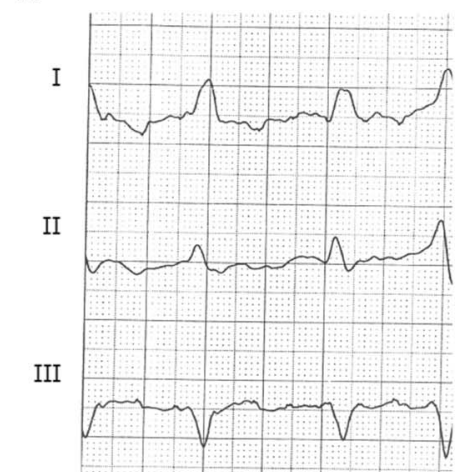

aVR

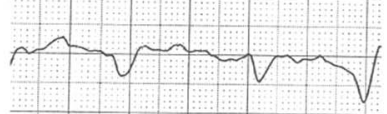

aVL

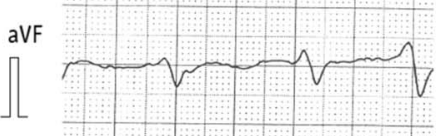

Heart rate: 139 bpm

V1

V2

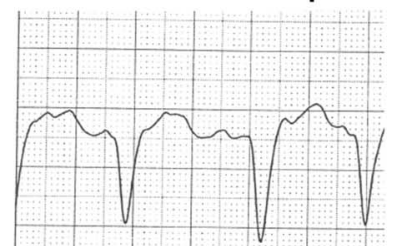

V3

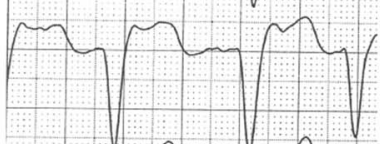

V4

V5

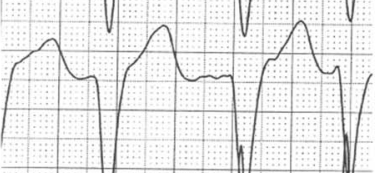

V6

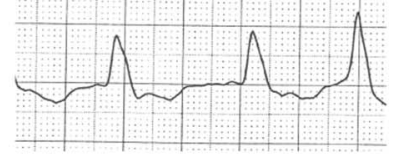

B

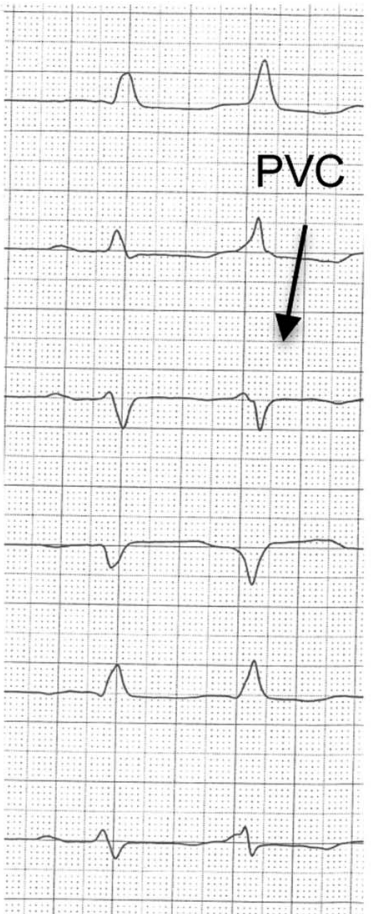

$64 \mathrm{bpm}$

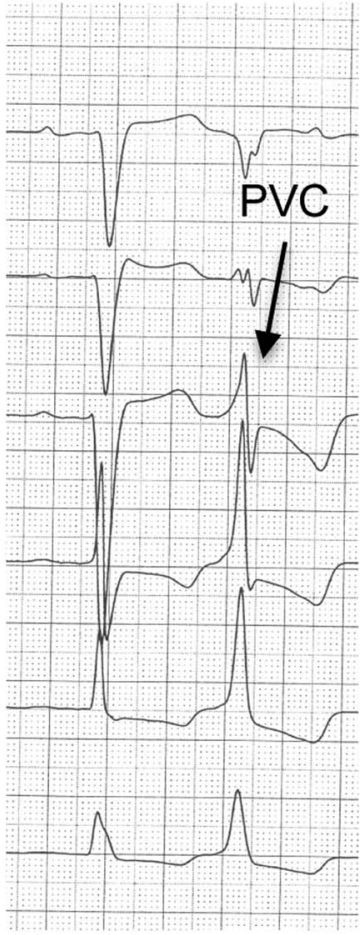

C

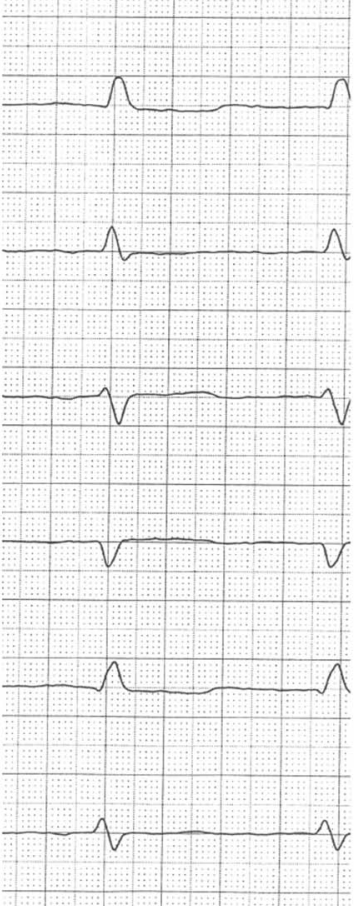

$58 \mathrm{bpm}$

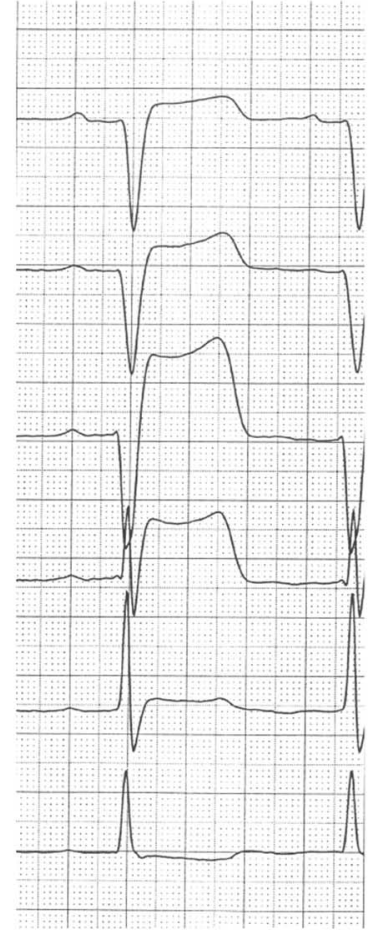

$50 \mathrm{~mm} / \mathrm{s}$
D

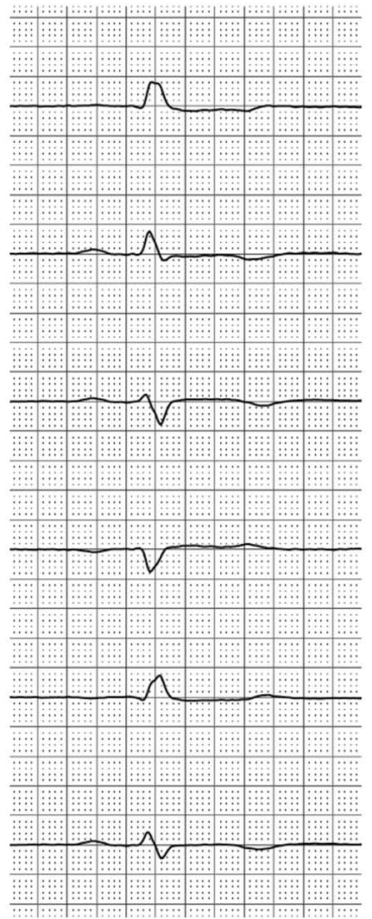

$63 \mathrm{bpm}$

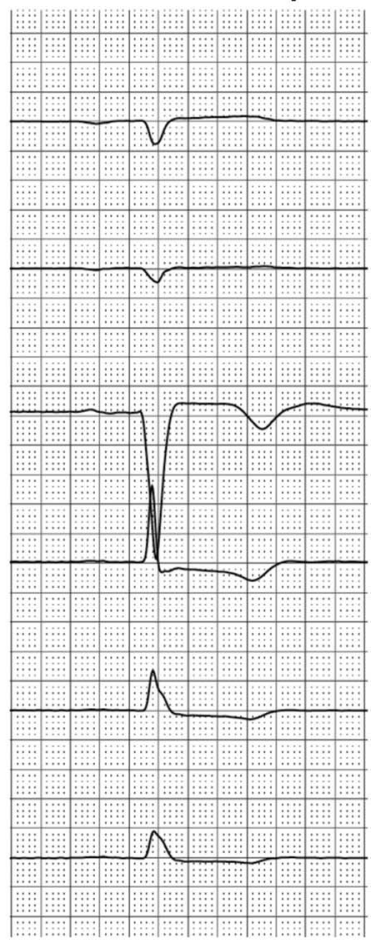

$500 \mathrm{~ms}$

Figure 1. 12-lead-electrocardiograms (ECG) of the patient. A, ECG at admission showing atrial fibrillation with rapid ventricular rate. B, ECG after cardioversion with sinus rhythm and premature ventricular beat (black arrows). C, ECG at one hour following cardioversion with marked ST-elevation in the anterior leads. D, ECG two hours after PCl of the left main coronary artery with poor R-wave progression but no ST-segment elevation. PVC, premature ventricular beat. 

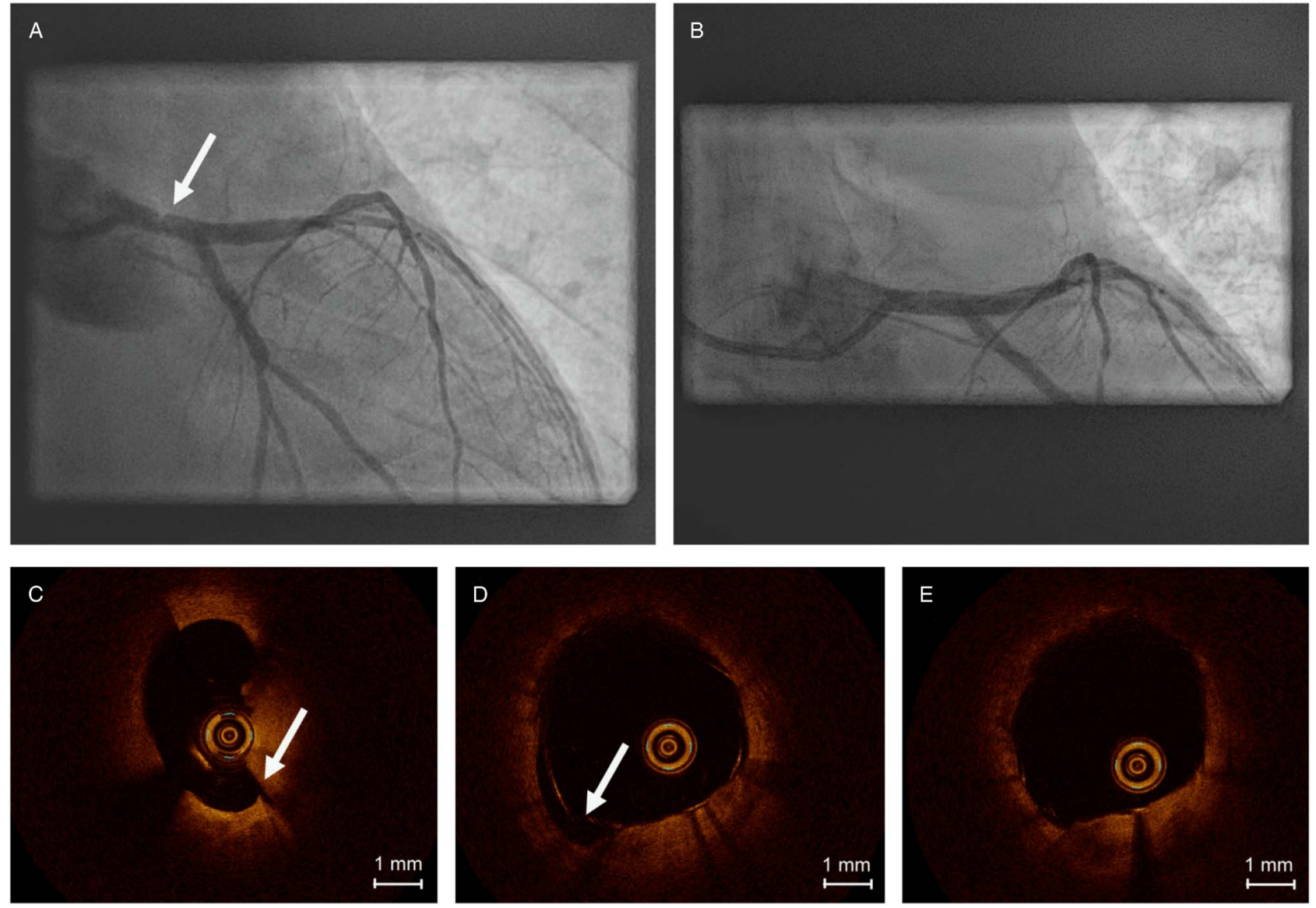

Figure 2. Coronary angiography $(A, B)$ and optical coherence tomography (OCT) findings (C-D). A, Coronary angiography revealed an eccentric plaque (white arrow) in the left main coronary artery with angiographically defined stenosis severity of $30 \%$. B, Angiography of left main coronary artery after stent deployment. C, OCT demonstrated plaque in the left main coronary artery with intimal disruption (white arrow). D, OCT with incomplete expansion after stent deployment with malapposed struts (white arrow). E, final OCT after second dilatation with non-compliant balloon showing adequate expansion of the stent.

risk of stroke. In our case, subsequent transesophageal echocardiography in preparation for a second attempt of cardioversion disclosed left atrial appendage thrombi despite the assumed effective long-term OAC, and it might have been considered fortunate, therefore, that no stroke occurred following the first cardioversion. Although anecdotal, this case suggests an advantage of rate-control as first-line therapy; as has been suggested, especially in an otherwise stable patient with an estimated higher $\mathrm{CHA}_{2} \mathrm{DS}_{2}$-Vasc-Score. ${ }^{7}$ If rhythmcontrol is the chosen therapeutic strategy, transesophageal echocardiography should be performed before cardioversion, even if the patient is believed to be on chronic OAC (especially when it is unknown whether a continuous OAC with target INR 2-3 for at least 3 weeks was indeed ensured). ${ }^{6}$
Second, there is another interesting aspect in our reported case. ST-segment elevation following cardioversion is a well-known phenomenon. In a case series of 91 patients referred for cardioversion of $\mathrm{AF}$, it was demonstrated that $35 \%$ of the patients developed transient ST-segment elevations. ${ }^{8}$ Although several theories have been suggested for these ST-segment elevations, the exact mechanism has not yet been clearly established. Actually, there is no evidence that cardioversion is combined with an increased risk of myocardial infarction. Prior work has shown that cardiac markers usually do not increase after direct current (DC) cardioversion. ${ }^{9}$ Moreover, using myocardial scintigraphy, it has been demonstrated that the STsegment elevation observed after DC cardioversion does not necessarily indicate myocardial injury. ${ }^{10}$ 
However, in our patient the ST-segment elevation was combined with acute chest pain. Even though the plaque rupture in the LMCA was not flow limiting, the chest pain resolved after immediate percutaneous coronary intervention (PCI).

\section{CONCLUSION}

ST-segment changes following DC shock cardioversion of AF are common, but usually short-lived and without clinical significance. Whether the ST-segment elevation in our patient was due to ST-elevation myocardial infarction (STEMI) or just a consequence of the cardioversion is unclear. Furthermore, the relevance of the lesion in the left main coronary artery is also speculative. However, immediate cardiac catheterization is mandatory in patients with ST-elevation and suspicious symptoms (if not otherwise contraindicated).

Competing Interests: None to declare.

\section{REFERENCES}

1. Stewart S, Hart CL, Hole DJ, et al. A population-based study of the long-term risks associated with atrial fibrillation: 20-year follow-up of the Renfrew/Paisley study. Am $\mathcal{J}$ Med 2002;113(5):359-64.

2. Barrett TW, Martin AR, Storrow AB, et al. A clinical prediction model to estimate risk for 30-day adverse events in emergency department patients with symptomatic atrial fibrillation. Ann Emerg Med 2011;57(1):1-12.
3. Stiell IG, Macle L, Committee CCSAFG. Canadian Cardiovascular Society atrial fibrillation guidelines 2010: management of recent-onset atrial fibrillation and flutter in the emergency department. Can 7 Cardiol 2011;27(1):38-46.

4. Ballard DW, Reed ME, Singh $\mathrm{N}$, et al. Emergency Department Management of Atrial Fibrillation and Flutter and Patient Quality of Life at One Month Postvisit. Ann Emerg Med 2015;66(6):646-54.e2.

5. Capucci A, Lenzi T, Boriani G, et al. Effectiveness of loading oral flecainide for converting recent-onset atrial fibrillation to sinus rhythm in patients without organic heart disease or with only systemic hypertension. Am 7 Cardiol 1992;70(1):69-72.

6. Fuster V, Rydén LE, Cannom DS, et al. ACC/AHA/ESC 2006 guidelines for the management of patients with atrial fibrillation-executive summary: a report of the American College of Cardiology/American Heart Association Task Force on Practice Guidelines and the European Society of Cardiology Committee for Practice Guidelines (Writing Committee to Revise the 2001 Guidelines for the Management of Patients With Atrial Fibrillation). European Heart Rhythm Association; Heart Rhythm Society. $f$ Am Coll Cardiol 2006;48:854-906.

7. Atzema CL, Barrett TW. Managing atrial fibrillation. Ann Emerg Med 2015;65(5):532-9.

8. Rumeau P, Fourcade J, Duparc A, et al. ST-segment changes after direct current external cardioversion for atrial fibrillation. Incidence, characteristics and predictive factors. Int 7 Cardiol 2011;148(3):341-6.

9. Rao AC, Naeem N, John C, et al. Direct current cardioversion does not cause cardiac damage: evidence from cardiac troponin T estimation. Heart 1998;80(3):229-30.

10. Shan $\mathrm{P}$, Lin J, Xu W, Huang W. ST-segment elevation after direct current shock mimicking acute myocardial infarction: a case report and review of the literature. Am 7 Emerg Med 2014;32(11):1438 e1-3. 